\title{
A randomised controlled trial of the effect of the provision of free school milk on the growth of children
}

\author{
IAN A. BAKER, PETER C. ELWOOD, JANIE HUGHES, MARION JONES, \\ FRED MOORE, AND PETER M. SWEETNAM
}

From the Epidemiology Unit, Medical Research Council, Cardiff

SUMMARY A randomised controlled study was carried out of the effect on growth of the provision of free milk supplements to schoolchildren aged 7 and 8 . In selecting children for this study, the aim was to identify those whose socioeconomic circumstances might place them at a disadvantage for growth. Five hundred and eighty-one children were selected from schools where a high proportion of the pupils received free school meals, and from families with four or more children. The subjects were randomly allocated to receive a third of a pint $(190 \mathrm{ml})$ of free milk daily for six school terms or to a control group. The mean difference in height gain at the end of twenty-one-and-a-half months was $3 \%$ or $2.93 \mathrm{~mm}(\mathrm{P}<0.05)$ in favour of the children provided with free milk. The mean difference in weight gain was $130 \mathrm{~g}(\mathrm{P}>0.05)$ in their favour. The height and weight gain associated with the provision of free milk was very small in the study population, and it is therefore likely that the benefit to growth of providing free milk for the whole unselected population of schoolchildren of these ages would be even smaller.

In 1934 , subsidised milk was made available for schoolchildren by government intervention. In 1944, under the Education Act, a third of a pint of milk was provided free of charge daily for all schoolchildren in government maintained schools. These provisions were part of increasing welfare programmes enacted by governments at a time of economic depression and wartime difficulties. After a period of improved economic and social conditions in the 1950s, renewed financial constraints in the 1960 s led to the withdrawal of free milk supplies to children in secondary schools in 1968. In 1971, the Minister of Education put forward alternative priorities in primary education and withdrew the free milk supply for children aged 7 to 11, except for those designated as 'in need' by school medical officers. Until this time, the provision and withdrawal of school milk appeared to be part of general social welfare programmes rather than resulting more specifically from nutritional or health policies. Indeed, it was only in response to questioning in the House of Commons about the possibly harmful effects on health as a result of the withdrawal of milk that the Government Committee on Medical Aspects of Food Policy (COMA) was asked to become involved in this matter. ${ }^{1}$

In 1926 a controlled experiment by $\mathrm{Dr}$. Corry-Mann ${ }^{2}$ demonstrated that a daily supplement of one pint of milk could increase growth by height in boys aged six to 11 by $43 \%$ or $2 \mathrm{~cm}$ in one year. In 1976 a COMA sub committee on nutritional surveillance accepted a proposal that a similar study concerned with the provision of a quantity of milk similar to that previously available in schools would provide important information on the effect on contemporary growth of such a dietary supplement.

\section{Method}

Twenty-five schools in Mid Glamorgan, South Wales, were selected because $20 \%$ or more of their pupils were receiving free school meals. To be eligible for free school meals a child must be a member of a family whose socioeconomic circumstances qualify for this benefit according to criteria laid down by the Department of Education. Within these schools, pupils who were aged 7 or 8 on 1 September 1976 were identified. The possibility of limitations on the nutrition and growth of these children was strengthened by selecting as subjects only those who belonged to families with four or more children. The children selected were randomly allocated within schools to a group provided with one third of a pint $(190 \mathrm{ml})$ of free milk daily for six school terms, or to a control group which was given no milk. Measurements of height with a Holtain 
stadiometer and of weight by beam balance were made by the same observer at the beginning of the study and on six subsequent visits over two school years. This observer was 'blind' to the group allocation of the children. Subjects in the milk-provided group drank their milk with children at the school who were receiving milk on medical grounds. The drinking of milk was supervised by school secretaries or members of the teaching staff. A second observer asked subjects on each visit whether they were drinking milk at school and the responses were recorded.

The method of selection described above was intended to identify children with some possible nutritional and growth disadvantage in whom any benefit from the provision of free milk could be most clearly demonstrated. In order to assess the effect of selection on the initial attained heights and weights of subjects, a stratified random sample was drawn from the total population of children in the county of Mid Glamorgan of the same age groups. The sample was stratified in four strata by the percentage of pupils receiving free school meals and eight schools were randomly selected from each stratum. All children in these schools who were aged 7,8 , or 9 on 1 September 1977 were measured for height and weight by the same single observer as in the milk study. The parents of these children were requested to complete a questionnaire which asked for information concerning the number of children in the family, whether or not it was a single-parent family, social class by father's occupation, and employment or unemployment status of the father. Those children who were measured, and for whom the above information from the questionnaires was complete, were included in the results. As the sample was stratified, the characteristics of the children were weighted according to the proportion of the total population which was contained in each of the above strata. Comparison of characteristics of children in the milk study was then made with the same characteristics of children in the county of Mid Glamorgan from which the milk study sample was drawn.

\section{Results}

By the time of the last follow-up visit $8 \%$ of the 581 children selected for the milk study had dropped out by being persistently absent or leaving the area. In the larger stratified random sample 3694 children were measured and $3337(90 \%)$ of the questionnaires were completed. The information for social class, number of children in the family, and number of single-parent families was complete for $93 \%, 98 \%$, and $\mathbf{9 8 \%}$ of 3337 questionnaires.
In Table 1 various characteristics of children in the milk study population are compared with similar characteristics of children in the county of Mid Glamorgan a year later. The socioeconomic disadvantage of the milk study children is indicated by the higher proportions in Social Classes IV and V and of those with unemployed fathers. Selection of the milk study population from families with four or more children shows that this population was drawn from just over $20 \%$ of the children in the county. The percentage of single-parent families was smaller in the milk study population, possible because these families tend to have smaller numbers of children. Only a fifth of the schools in Mid Glamorgan have proportions of children receiving free school meals similar to those in the schools from which the milk trial population was drawn.

The mean attained heights and weights by age at initial examination are shown in Table 2 for the milk study children and for the children of Mid Glamorgan. Children in the milk study were $2-3 \mathrm{~cm}$ shorter and $1.5 \mathrm{~kg}$ lighter than children in the county generally. It appears, therefore, that the manner of selecting children for the milk study resulted in a population who were of diminished growth, in whom any benefits from the provision of free milk might be best demonstrated.

Table 1 Proportions of children with various characteristics in the school milk trial and Mid Glamorgan

\begin{tabular}{lll}
\hline & School milk trial $\underset{\%}{\text { Mid Glamorgan }}$ Characteristic & $\%$
\end{tabular}

\begin{tabular}{|c|c|c|}
\hline \multicolumn{3}{|l|}{ Social Class } \\
\hline I & $0 \cdot 0$ & $1 \cdot 7$ \\
\hline II & $1 \cdot 5$ & $12 \cdot 9$ \\
\hline III & $40 \cdot 8$ & $46 \cdot 4$ \\
\hline IV & $19 \cdot 3$ & $15 \cdot 6$ \\
\hline V & $6 \cdot 0$ & 2.4 \\
\hline \multicolumn{3}{|l|}{ Father's employment } \\
\hline Unemployed & $23 \cdot 1$ & $18 \cdot 9$ \\
\hline Others & $9 \cdot 3$ & $2 \cdot 1$ \\
\hline \multicolumn{3}{|l|}{ No. of children in family } \\
\hline$<4$ & $0 \cdot 0$ & $77 \cdot 8$ \\
\hline $4-5$ & 79.5 & $18 \cdot 6$ \\
\hline$\geqslant 6$ & $20 \cdot 5$ & $3 \cdot 7$ \\
\hline Single-parent families & $7 \cdot 9$ & $9 \cdot 2$ \\
\hline $\begin{array}{l}\text { Schools with } 20 \% \text { or more } \\
\text { free school meals }\end{array}$ & $100 \cdot 0$ & $19 \cdot 0$ \\
\hline
\end{tabular}

Table 2 Mean attained height and weight by age for children in the school milk trial and Mid Glamorgan

\begin{tabular}{lll}
\hline Age & $\begin{array}{l}\text { School milk trial } \\
\text { Height }(\mathrm{cm})\end{array}$ & $\begin{array}{l}\text { Mid Glamorgan } \\
\text { Height }(\mathrm{cm})\end{array}$ \\
\hline $7-$ & $120 \cdot 6$ & 123.4 \\
$8-$ & $126 \cdot 3$ & $128 \cdot 3$ \\
$9-$ & 130.2 & 133.5 \\
& Weight $(\mathrm{kg})$ & Weight $(\mathrm{kg})$ \\
$7-$ & 23.1 & 24.8 \\
$8-$ & 25.8 & 27.1 \\
$9-$ & 28.7 & 30.2 \\
\hline
\end{tabular}


A randomised controlled trial of the effect of the provision of free school milk on the growth of children 33

During the milk study, three subjects in the control group received milk and thirteen subjects in the milk-provided group disliked milk and did not drink it. The measurements of these small numbers of subjects were ascribed to the groups of the subjects' initial allocation. The mean age of subjects entered into the milk study and their mean initial attained height are shown in Table 3 . Mean attained height was $4 \mathrm{~mm}$ greater in the control group. The mean time interval between the first and last measurements was just over twenty-one-and-a-half months for both groups.

Growth by height and weight over this total duration of the study is shown in Table 4. The difference in growth is approximately $3 \%$, both for the height gain of $2.8 \mathrm{~mm}$ and the weight gain of $130 \mathrm{~g}$, in favour of those children within the group provided with free milk. Growth in height over any period relates to the attained height of subjects at the beginning of the period. In this study subjects in the control group had an initial mean attained height slightly greater than subjects in the milk-provided group. This difference in height may act to diminish the difference in height gain between the milk-provided group and the control group. An analysis of covariance was undertaken to allow for the effect on the heights of subjects in the two groups recorded at the last visit of their heights at the initial visit. By this analysis, the adjusted mean height of subjects in the milk-provided group was $2.93 \mathrm{~mm}$ greater than the adjusted mean height of subjects in the control group at the last visit.

Growth for both groups by sex is also shown in Table 4. The overall differences in growth are by

Table 3 Characteristics of the two groups for subjects measured on the first and seventh visits

\begin{tabular}{|c|c|c|}
\hline & Milk-provided & Controls \\
\hline No. & 281 & 239 \\
\hline $\begin{array}{l}\text { Mean age in years } \\
\text { (SD) }\end{array}$ & $8.04 \quad(0.55)$ & $8.04 \quad(0.58)$ \\
\hline $\begin{array}{l}\text { Mean height on 1st visit in } \mathrm{cm} \\
\text { (SD) }\end{array}$ & $(6 \cdot 31)$ & $124 \cdot 1$ \\
\hline $\begin{array}{l}\text { Mean time interval in months } \\
\text { (SD) }\end{array}$ & $21.56 \quad(0.28)$ & $21.53(0.26)$ \\
\hline
\end{tabular}

height of $1.1 \mathrm{~mm}$ for boys and $4.5 \mathrm{~mm}$ for girls, and by weight of $210 \mathrm{~g}$ for boys and $50 \mathrm{~g}$ for girls. As some of the older children may have been approaching their pubertal acceleration of growth by the end of the study period, the effect on growth by height was considered separately for the two different age groups involved. There was, however, no evidence that growth varied significantly with the age groups in both sexes combined or separately, according to the provision of free school milk.

Growth with the provision of free school milk may also have varied with the social class or employment status of the fathers of the families from which the subjects were drawn. Groupings of Social Classes I, II, and III, and IV and V, revealed no evidence that the effect on growth by height of the provision of free school milk varied with social class. Similarly, no variation in growth by height was demonstrated according to employment or unemployment status of fathers.

The fourth visit took place approximately twelve months after the commencement of the trial. Five hundred and thirty-three subjects were seen and measured at this time. The differences in mean height and weight gain for both sexes combined $(1.9 \mathrm{~mm}$ and $130 \mathrm{~g})$, and for boys $(2.0 \mathrm{~mm}$ and $210 \mathrm{~g})$ and for girls $(1.8 \mathrm{~mm}$ and $50 \mathrm{~g})$ for the milk-provided groups over the control groups, were consistent with the differences found at the seventh visit at the end of the trial.

\section{Discussion}

With the existence of historical evidence supporting a benefit to growth in the height of children from the supplementation of their diets with milk, and the continuing debate on the advisability of providing free milk supplements to schoolchildren aged 7 to 11 , it seemed reasonable in the absence of such free provision to mount a study to consider this form of possible benefit. The results of the study indicate that the benefit to growth by height and weight over two school years is very small, although statistically significant at the $5 \%$ level of probability for height gain in both sexes combined. The $95 \%$ confidence limits for the 'true' effect of milk provision on height gain in the population from which this sample was

Table 4 Growth in subjects between first and seventh visits

\begin{tabular}{|c|c|c|c|c|c|c|}
\hline & \multicolumn{3}{|l|}{ Milk-provided } & \multicolumn{3}{|l|}{ Controls } \\
\hline & Total & Boys & Girls & Total & Boys & Girls \\
\hline No. & 281 & 144 & 137 & 239 & 123 & 116 \\
\hline Height in $\mathrm{cm}$ (SD) & $9.46 \quad(1.68)$ & $9.21 \quad(1.35)$ & $9.72 \quad(1.94)$ & $9.18 \quad(1.67)$ & $9 \cdot 10 \quad(1.40)$ & $9.27 \quad(1.91)$ \\
\hline Weight in $\mathbf{~ k g}$ (SD) & $5.25 \quad(2.26)$ & $4.94 \quad(2.16)$ & $5.58 \quad(2.33)$ & $5.12 \quad(1.90)$ & $4.73 \quad(1.45)$ & $5.53 \quad(2.21)$ \\
\hline
\end{tabular}


drawn are $0.1 \mathrm{~mm}$ to $5.8 \mathrm{~mm}$ over two school years. There is no evidence that the provision of free milk affects boys and girls differently, hence our results were considered for the combined sexes as well as singularly. The mean height gain differences for boys and girls in the milk-provided groups separately did not achieve statistical significance.

The limited extent of the growth differences associated with the provision of free milk must be considered further in relation to the selection of schoolchildren in this study. Selection determined a population of children at some socioeconomic 'disadvantage' in comparison with the total population of children of the same age in the same geographical location. This 'disadvantage' was associated with lower levels of attained height and weight. It would seem likely, therefore, that the effects of the provision of free milk on growth in the total unselected population of schoolchildren aged 7 and 8 , and possibly in the whole range of children aged 7 to 11 , would be even smaller. The time interval of the study covered half the number of school years in which milk can be available for schoolchildren aged 7 to 11 .

The limited increase in growth of subjects in the milk-provided group probably reflects a reasonable state of general nutrition even in this 'disadvantaged' population. Within this population there was no further evidence that the provision of free milk affected growth differently by the social class or employment status of the fathers. Cook et al. (unpublished observations) determined by questionnaire the amount of milk drunk at home by . schoolchildren aged 6 and 7 in manual social classes drawn from England and Scotland in 1972 to 1976. Only $2 \%$ of children drank no milk at home. Also, they found no difference in height gain in one year in these children according to the amount of milk drunk per day at home or at school. It is unlikely that a more marked effect on growth would have occurred had a larger volume of free milk been provided. A third of a pint $(190 \mathrm{ml})$ is the customary amount provided by the government or local authorities. The milk was drunk under supervision, but the amount of wastage was not known. In these ways the design of the study related to the conditions which normally occur with the provision of free milk to schoolchildren.

Free milk supplements may have effects other than on growth, which may be beneficial or harmful. These effects remain to be determined by further studies.

We thank the Director of Education, the District Education Officers, the headmasters, headmistresses, staffs, and pupils of Mid Glamorgan for their co-operation in this study.

Reprints from Dr. I. A. Baker, MRC Epidemiologyo Unit, Cardiff CF2 3AS.

\section{References}

${ }^{1}$ Lancet. Editorial: Parliament: school milk. Lance 1971;1:1359.

${ }^{2}$ Corry-Mann HC. Diets for boys during the school age." Medical Research Council Special Report Series No. 105. London: HMSO, 1926. 